\title{
Stray Load Losses in Induction Machines A Review of experimental measuring Methods and a critical Performance Evaluation
}

\author{
H. Köfler ${ }^{1}$ \\ ${ }^{1}$ Institut für Elektrische Maschinen und Antriebstechnik, \\ Fakultät für Elektrotechnik und Informationstechnik, \\ Technische Universität Graz \\ Kopernikusgasse $24-, 8010$ Graz (Austria) \\ phone:+316 873 8600, fax:+316 873 8103, e-mail: Koefler@ema.tu-graz.ac.at
}

\begin{abstract}
As stray load losses are the most unknown element of the balance of power in induction machines a number of theories how to calculate and to measure these losses exist. The following intends to describe, compare and criticise a number of different measuring methods performed with the same machine. By discussion of the theoretical background of additional losses the deficiencies of the different methods can be seen. The comparison of the results delivers surprising equalities of methods in the loss values but also very disturbing false measurements which might support the engineering community in sticking to the convenient percentage value given in the standards. However to meet the stringent requirements of high efficiency motors a thorough investigation on measurement of stray load losses is still necessary.
\end{abstract}

\section{Key words}

Stray Load Loss, Additional Loss, Induction Machine.

\section{Introduction}

Standards report us that the stray-load loss is that portion of losses in a machine not accounted for by the sum of friction and windage, stator $\mathrm{I}^{2} \mathrm{R}$ loss, rotor $\mathrm{I}^{2} \mathrm{R}$ loss and core loss. This statement gives no special hints to uncover the origin of the losses. But theory of stray load losses is well documented in the L. Dreyfus publications "Theorie der zusätzlichen Eisenverluste in Drehstromasynchronmaschinen" [1]. From this extensive discussion we learn the class of losses that may be measured in the different proposed measuring schemes. There are two different classes belonging to eddy current losses and to hysteretic losses which in fact often are summarised under the idea of additional iron losses. Most of the theory tackles the eddy current losses and states that the hysteretic losses are difficult to grasp. The fact that additional losses are connected with higher harmonics and therefore also merely with surfaces reduces the disregarding of the hysteretic losses to a less prominent problem. In a review in $1985 \mathrm{Jimoh}$, Findlay and Poloujadoff [2] treated the problem of stray-load losses (additional losses, reviewed a number of experimental methods but evaluated these methods by problem statements and not by comparison of the results gained at the same machine by these various methods. In the following this result comparison for some of the proposed schemes [3] is done and discussed for a $5.5 \mathrm{~kW}$ motor. Problems still arising in large machines with these methods will be also addressed.

\section{Review of Theory}

Pulsations of flux in teeth of stator and rotor and in the air gap are the main origin of additional losses in induction machines. The pulsation is due to the change of reluctance of the magnetic path of teeth during the movement of the stator teeth against the rotor teeth (reluctance modulated harmonics) and the fluctuation of ampere turns according to the distributed imbedding of the current carrying conductors in the slots (ampere turns based harmonics). The frequencies of both the series of harmonics are the same however they are time shifted against each other. More precisely we have to say that in the stator there are stator $\mathrm{MMF}$, rotor $\mathrm{MMF}$, slot ripple modulated by the stator and saturation components of the harmonics, and in the rotor we find components from slip-frequency currents caused from the main flux fundamental, currents due to the stator MMF distribution, slot ripple due to stator teeth, saturation and currents impressed by harmonic fluxes. As we are interested in losses and their implication on thermal behaviour of machines we do not include all this in our review. What is more striking for the purpose of this paper is the question of the current dependence of the stray load losses. Very clear is that the ampere turns based harmonics depend on the current. The reluctance modulated harmonics depend upon the magnetisation of the magnetic path and depend therefore on the voltage level supplied to the machine. As far as the supply does not exceed the nominal value the losses due to possible reluctance modulated harmonics should be included in the measured no load losses. If the supply voltage is raised to levels higher then nominal the no load current is raised too and approaches nominal current values. This current with respect to reluctance caused harmonics should act as we stated already. One can postulate that harmonics and associated losses depend on the square of 
currents [4] flowing in the windings of the machines. Together with this postulate we dare to omit hysteretic losses as the expected minor loops should not contribute essentially to the main part of hysteretic losses. We are now in a position to search for tests in which we can separate the stray losses from other losses. The standards have already adopted the dependence of stray-load losses from current and give guidance how to get the relevant current. In this connection the no load current is decisive as stray- load losses in the standard are present only at load. However if the test to acquire losses to be counted as additional losses one observes that depending on the design of the machine these losses are also present to some extent at no load and the deviation of the core loss curve from its linear dependence can start at currents lower than the no load current at rated voltage (this means in no load test of course a voltage and flux level lower than nominal). Moreover in this connection one must be aware that one is searching for small quantities of power compared to full power of the machine. Any experiment where we can acquire merely losses puts us in the position of balancing small quantities against each other. This will improve the accuracy of the loss determination. The direct method namely subtracting input power and output power from the accuracy viewpoint is difficult. The machine under examination is a little curious as the rotor winding of single layer structure is embedded in as much as sixty narrow rotor slots. By simple inspection we have to notice that these sixty rotor slots must produce reluctance based cogging torques with the thirty six stator slots. Three complete stator slots are opposed from five complete rotor slots by this forming a twelve pole saliency.

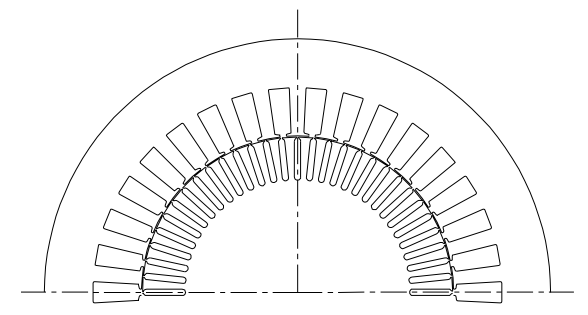

Fig. 1 Cross section of the machine investigated

\section{Measurement of Stray-Load Losses}

In the course of this paper the following methods for determination of stray losses are used:

1
2
3
4
5
6

No Load Test
Differential Method
Input Output Method
AC/DC Short Circuit Method
Reverse Rotation Method [5]
Eh-Star connection with auxiliary
resistance unbalanced Method [6]

In test 1 and 2 a synchronous machine is used to drive the induction motor by this eliminating the friction losses and the $\mathrm{I}^{2} \mathrm{R}$ losses of slip born currents in the rotor. The motor is excited to high saturation level step by step. During the test the power necessary to magnetise the asynchronous machine is measured continuously. In a variation of this test in 2 the power necessary to drive the synchronous machine is measured in addition. One is disposed to assume that the introduction of a calibrated synchronous machine simply removes the burden of the friction losses from the induction machine at test. However we are not searching for effects described by plain theory of sine distributed fundamental space harmonic MMF. Stray losses are by definition linked with harmonics and the torques produced by these harmonics can be asynchronous as well as synchronous. At fundamental synchronous speed the torques may be either motor or generator. The value should be seen in the change of the power consumption of the synchronous machine although we cannot distinguish the components but only the final sum of that torques.

But in the first step we will give the figures from test 3 . In 3 the induction motor is running at full load. This input-output method is the first method mentioned in the standards to define efficiency of motors. The shaft power here is measured with a calibrated DC-generator. This method at a first glance should be the most accurate but the result with respect to stray load losses is built up by the balance of two large power values and therefore described to be very erroneous [2]. Nevertheless the outcome shall be the criterion for the results gained by the other test procedures. The diligent balance of power in the induction machine and in the calibrated load DC machine delivers $284.47 \mathrm{~W}$ for the additional losses (Stray-load losses) at full load of the machine. No experimental readings for partial load have been taken.

In the following test 1 is compared at two different temperature conditions of the motor. To get the final loss data for full load one has to define a square of a relevant stator current difference. In the standard is proposed to take the difference of the square of the load current at rated voltage and rated power and the square of the no load current at rated voltage. As can be seen from the figures the onset of additional losses in the test machine is at a lower current level equivalent to a lower voltage than rated at the no load test. The extrapolation of the core losses in the two subsequent tests at different temperature of the core give as to be expected also different core losses. Taking the higher loss value as a reference, we find that losses in the hotter test point are $2 \%$ lower. This is due to the greater resistance of the sheet material which reduces the eddy current losses in the core sheets. As stray load losses in the main portion are also eddy current losses we expect a similar behaviour for the results. This clearly is not in contradiction to the theoretical origin of the main part of these losses. Eddy current surface losses depend on the conductivity of the surfaces and therefore the losses in the hot case should be lower. However we do not know the percentage of this temperature born reduction as the conductivity to be used for calculation of the losses of the rotor and stator stack certainly is not the value known for the bulk sheet material. With respect to standards the author found an account for stray load losses due to temperature in the tests used in large transformers. In rotating machinery no 
special expressions with respect to iron or additional iron losses and temperature have been verified.

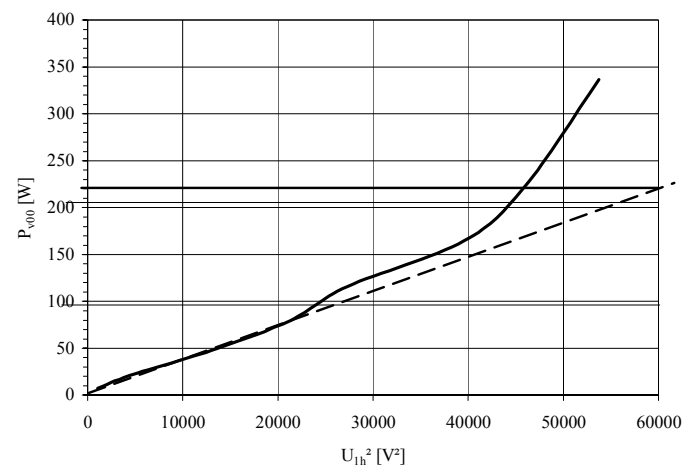

Fig. 2 Loss separation in No Load Test at warm machine (raw data)

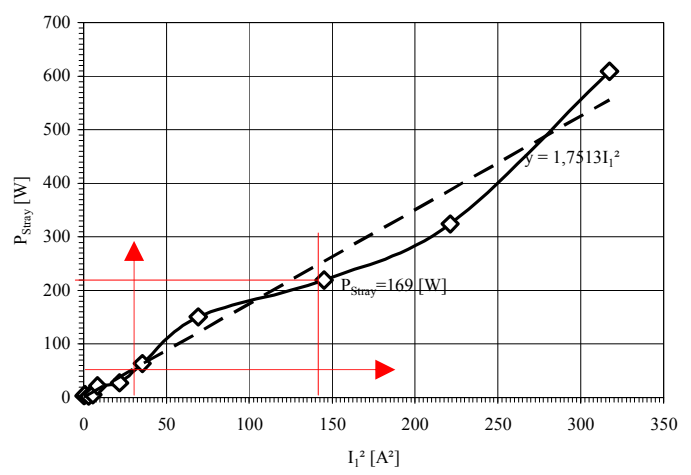

Fig. 3 Stray-load Loss from No Load Test at warm machine (processed data)

The linearised as well as the original data plotted against the square of the stator current show the expected behaviour with respect to temperature. We find from both experiments different results for the stray-load losses. In the so called warm test version (this is at nominal operating temperature) we find 165 Watt. This is 58 percent of the figure found with test 3 .

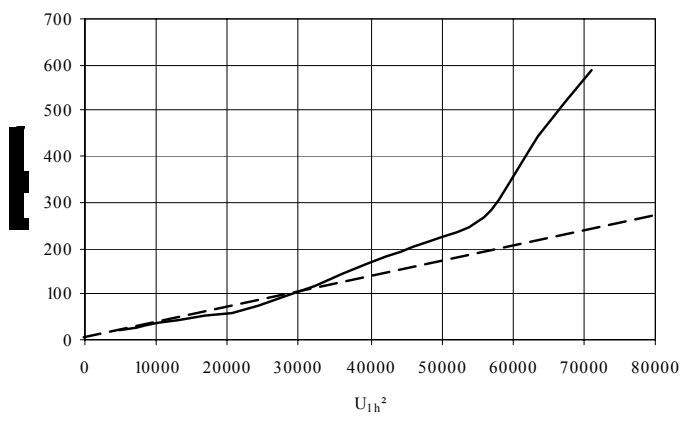

Fig. 4 Loss separation in No Load Test at hot machine (raw data)

The hot test at excess temperature delivers lower strayload losses $(147 \mathrm{~W})$. Either value of the losses measured does not match the result of test 3 . From the test procedure 1 we may conclude that the loss enhancement due to rotor currents is missing in the test described in number 1 .

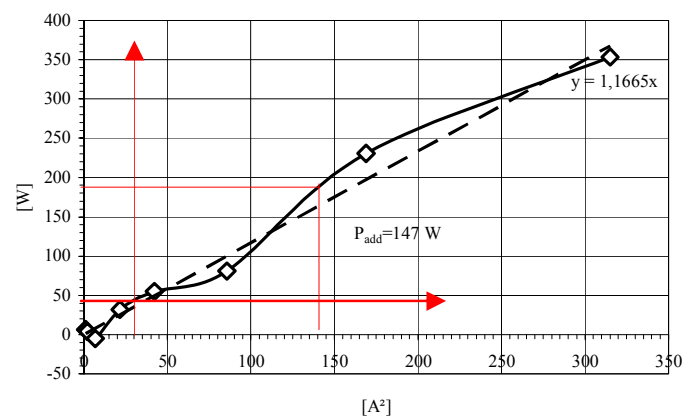

Fig. 5 Stray-load Loss from No Load Test at hot machine (processed data)

If one first assumes that losses of the stray-load class can be added separately and secondly losses depend on the square of the current present in the slot we may roughly assume that the rotor current (which in test 1 is not present) may cause $50 \%$ of the stray-load loss found from stator currents. The figure of $50 \%$ is chosen because the equivalent rotor current in the stator frame is lower than the stator current and the slot opening in the rotor even when all openings are added is smaller than in the stator. This idea of account ends up with $247.5 \mathrm{~W}$ or $220.5 \mathrm{~W}$ of final stray-load loss. This is not as far away from the value found in test 3 .

The traces for stray-load losses in the warm and in the hot case show different behaviour with respect to the deviation from the expected linear behaviour. The deviation suggests that at different stray-load loss levels a second overlay source of power is present. At high stray-load loss level in the warm machine an added generator and in the hot machine an additional motor seems to be present. In 4 the magnetising of the machine is no more by $\mathrm{AC}$ currents but by DC currents either in the stator or in the rotor. The not excited winding runs in a short circuit. In contrast to test 1 both windings carry current. Change in power to be supplied is measured at the terminals of the driving machine.

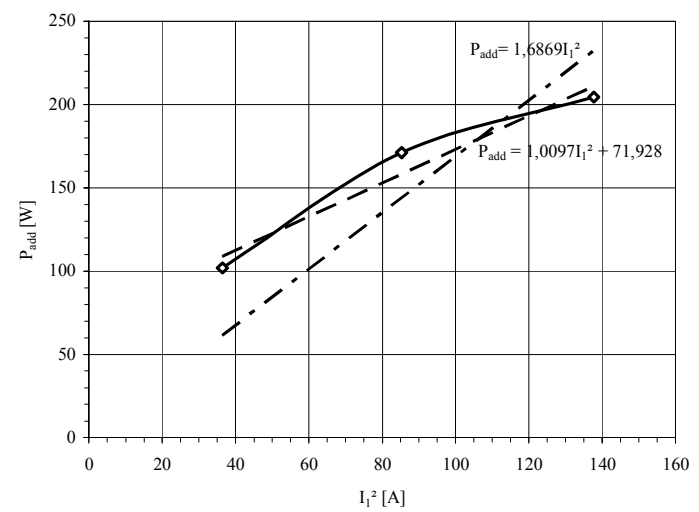

Fig. 6 DC excitation test with stator short circuited 
The result plotted against the square of the stator current delivers losses in the same range of magnitude as detected with other tests $(215 \mathrm{~W})$. A major difference is that the linear loss extrapolation to zero delivers a constant loss power of $72 \mathrm{~W}$. The curved loss trace however should end up at zero. When this zero point is added to the measured data another linear fit is found (shown in the figure too and delivering $239 \mathrm{~W}$ of additional losses). In 5 the induction machines rotor is driven against the rotation of the flux phasor which is produced by current levels equivalent to nominal in the stator (adjusted by low supply voltage). Both power-flows that into the asynchronous machine and that into the synchronous machine have to be controlled. The measured result for rated current is $216.8 \mathrm{~W}$.

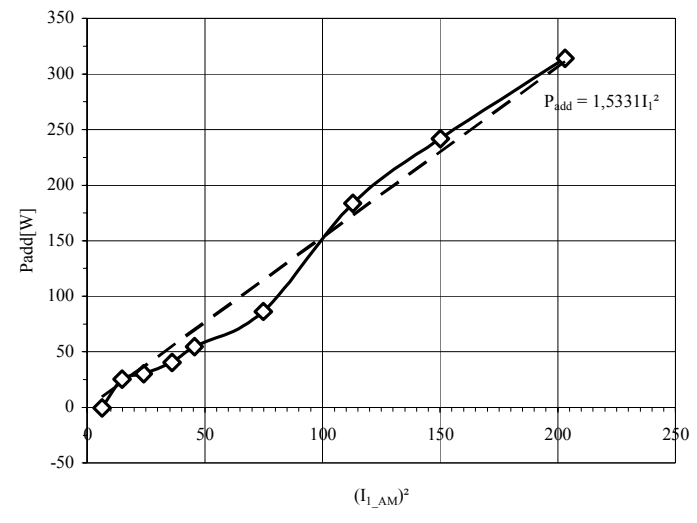

Fig. 7 Reverse rotation Test

6 in some aspects is a modification of 5. By unbalance of the supply voltages a reverse rotating flux phasor is produced. No driving machine is necessary. A remarkable difference is that the test is performed at main flux density levels nearly equivalent to rated operation of the induction machine whereas in the reverse rotation test the supply voltage had to be reduced to match the stator current limits. The wiring sketch below shows all features of the eh-Test. The Load or Drive machine in this test is disconnected. It is used in the other experiments when the eh-resistor is removed from the wiring path by proper switching.

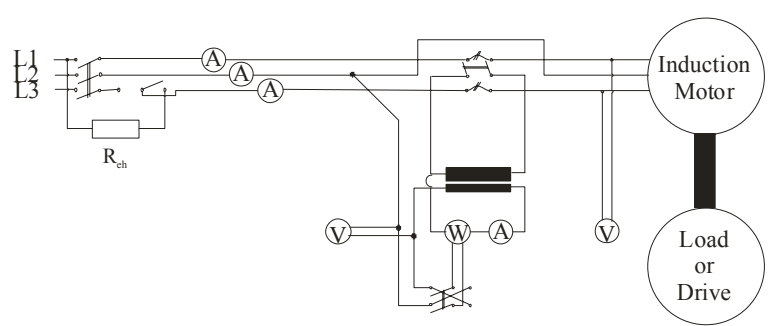

Fig. 8 Wiring Sketch eh_Test

Control of all phase currents and voltages is essential for this test. From the readings of currents, voltages, revolutions and power for a distinct value of eh-resistor the mathematical treatment starts. It includes calculation of positive phase-sequence systems and negative phasesequence systems. The formulas not presented deliver phase angels, amplitudes of positive phase-sequence systems of voltages and currents as well as negative phase-sequence systems of voltages and currents. All together is used favourable for the evaluation of strayload losses.

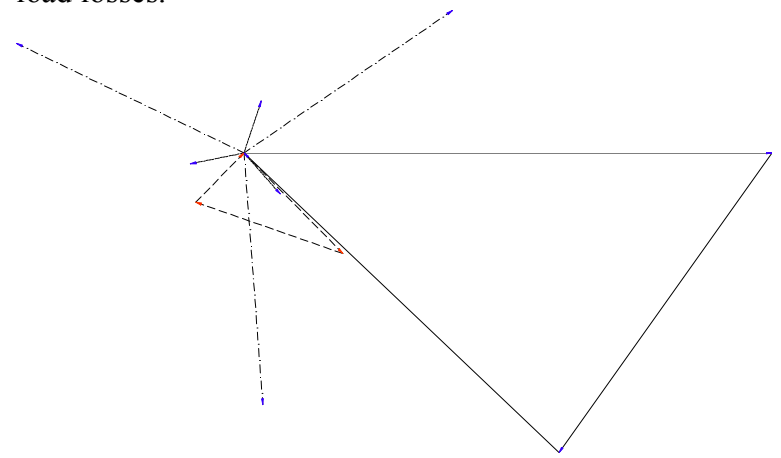

Fig. 9 Phasor diagram of measured and some calculated voltages (blue) and currents (red) at eh-test

The negative phase -sequence systems cause braking torques to be supplied from the positive phase-sequence systems. Careful account of already known losses of the test machine like core losses is necessary in the procedure. The balance of powers in the positive phase-sequence systems and the negative phase-sequence systems produces the result. The final value of the test and calculation procedure is $205 \mathrm{~W}$ at an unbalanced current set of 4.2, 8.6 and 9.5 Ampere in the supply L1, L2 and L3. The averaged effective current of this set is about 7.6 A. Therefore we ought to correct the losses. Standards base that correction on the squared relation of rotor current at test point and rotor current at projected load point. The rotor currents under these asymmetric test conditions have not been measured nor can be calculated easily. If the usual assumption of extrapolation is used for the extrapolation of positive and negative sequence additional losses one ends at the high loss value of $446 \mathrm{~W}$. So the conclusion to be drawn at that point is that the losses given above first at nominal load shall be larger than $205 \mathrm{~W}$ but lower than $446 \mathrm{~W}$.

\section{Conclusion}

What are the messages of the various methods? First of all one has to be careful when tests are called no-load tests as is done for
1 No-load test
2 Differential Method
5 Reverse rotation Method
6 Eh-Star connection with auxiliary resistance unbalanced Method

It is correct that in all these tests only small real power is measured but the apparent power of the No-Load test and the Differential Method with enhanced voltage trespasses by far the nominal rating of the machine tested. One must admit that the method from this point of view is not applicable in all test stands especially when machines with large power are involved. The differential method furthermore needs a second calibrated driving machine 
whereas 1 if the elimination of friction from the test machine is abandoned can be done at the standalone machine.

The further discussion tries to draw the attention again back to the basics of the additional losses. From the distribution of the ampere turns along the circumference of the stator bore follows together with the air gap distribution and the characteristic of the magnetic circuit the flux density distribution in the air gap of the machine. From the analytical approach we learn rather soft breaks of the B distribution due to slots. The related losses have been measured at test 1. As can be seen from Fig. 2 and 4 the losses are moderate. When one switches over to load the simple analytical approach is no more efficient. For that the FEM calculation in the plane cross section of the machine is applied.

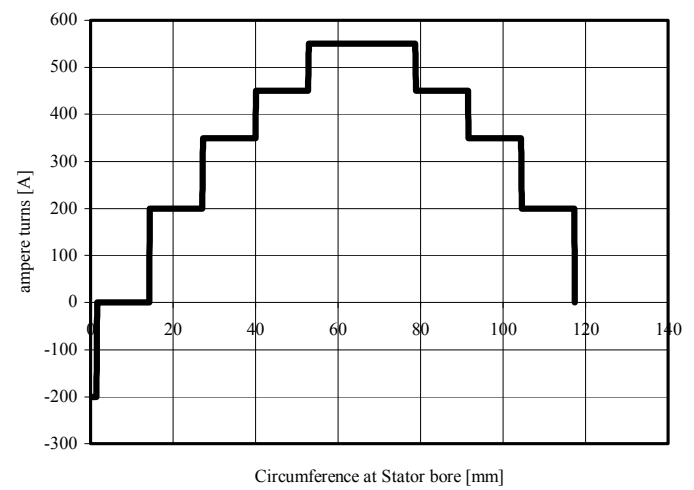

Fig. 10 Excitation distribution along the circumference $\left(I_{U}=1, I_{V}=-0.5, I_{W}=-0.5\right.$ p.u. $)$

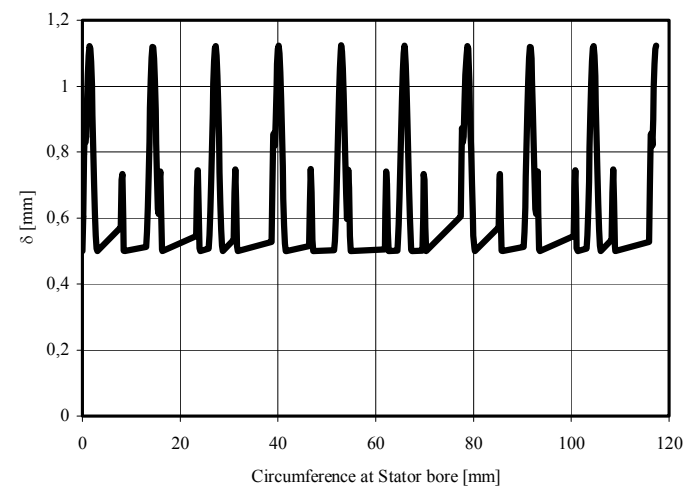

Fig. 11 gap distribution along the circumference according to Carter Factors

As the machines rotor has very narrow slot openings we have to expect widening of this slits by saturation due to the rotor currents. An attempt to show the difference between no-load a load B-trace in the gap gives Fig. 14. At no load and ideal assumptions the small rotor slot openings cause only very small breaks in the B-trace. As soon as saturation caused by the load current in the slots opens the rotor slots a very remarkable enhancement of breaks in the B-trace takes place.

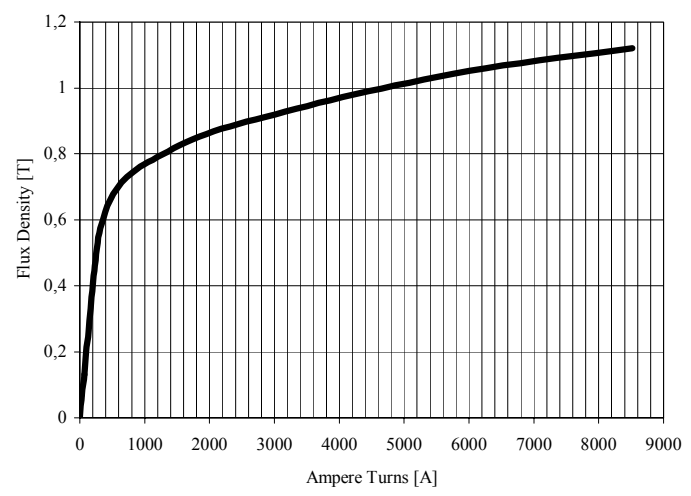

Fig. 12 Magnetic circuit characteristic over peak excitation

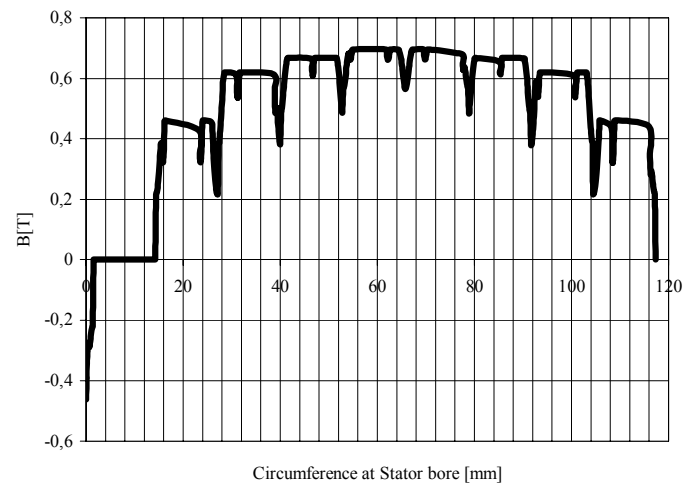

Fig. 13 Calculated Flux density distribution according to Carter factors along the bore circumference (stator excited, approximately no load condition)

Theory indicates that stray-load losses strongly depend from the deepness of the flux density breaks. As one can see from the presentations in calculated no load conditions the breaks are shallow. That observation is consistent with the small amount of stray-load loss present at ideal no load operation at rated voltage. The loss dependence is shown also by the formula below.

$$
\begin{aligned}
& P_{\mathrm{V}, \text { Arel, } \mathrm{j}}=\frac{1}{2} \cdot\left(\frac{2 \cdot \kappa_{\mathrm{j}}}{\pi \cdot 6}\right) \cdot \frac{1}{\tau_{\mathrm{N}, \mathrm{i}}} \cdot\left\{v \cdot \bar{B}_{\mathrm{r}, \mathrm{i}} \cdot \Delta^{\prime}\right\}^{2} \cdot O_{\mathrm{j}}^{\prime} \cdot \Sigma_{\mathrm{r}, \mathrm{O}^{\prime}, \mathrm{i}} \\
& \kappa_{\mathrm{j}} \quad \text { spec. cond. of "j" part }\left[\frac{1}{\Omega \cdot \mathrm{m}}\right] \tau_{\mathrm{N}, \mathrm{i}} \text { slot pitch of "i" part }[\mathrm{m}] \\
& v \quad \text { rel. surf. speed }\left[\frac{\mathrm{m}}{\mathrm{s}}\right] \quad \bar{B}_{\mathrm{r}, \mathrm{i}} \text { slotflux dens. swing in "i" part }[\mathrm{T}] \\
& \Delta^{\prime} \quad \text { lamination thickness with insulation }[\mathrm{m}] \\
& O_{\mathrm{j}}^{\prime} \quad \text { corrected area teeth heads in "j" part }\left[\mathrm{m}^{2}\right] \\
& \sum_{\mathrm{r}, \mathrm{O}^{\prime}, \mathrm{i}} \text { factor, sum of harm. contribution from "i" part }
\end{aligned}
$$

The raising of the supply voltage rapidly causes large stator currents by this turning the breaks in flux density course to the picture seen in the FEM calculation for full load. However it is impossible to observe the intensifying of breaks due to large rotor currents in the no load test driven by a synchronous machine. Nevertheless these ob- 
servations back up the modification of losses used in test 1 and 2. Further in the discussion of the results of some of these tests we check them with respect to the wavy appearance of the data. The wavy appearance is present in test 1,2 , and 5 .

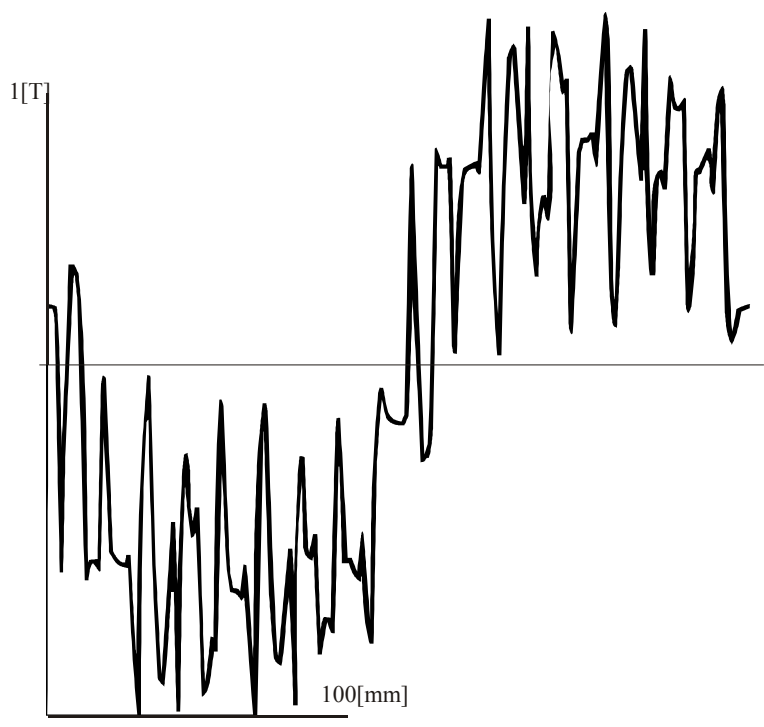

Fig. 14 Calculated Flux density distribution (FEM) along the bore circumference (stator and rotor excited, approximately full load condition)

In the text already an explanation was dared. The result of a calculation done with respect to that is shown in Fig. 16. The torque angle characteristic of the driving synchronous machine, stabilising the operating point, is superposed with a characteristic of a very weak synchronous machine established by the saliency of the induction motor. As one can see the machines together produce the observed behaviour when considerable pole angle swing in the synchronous machine occurs. This is possible when the driving synchronous machine is operated under low voltage to allow sufficient readings in the instruments. The different behaviour in the two experiments with respect to this effect seems to be random as the power level in both the experiments is approximately the same. The very same behaviour can also be observed in the reverse rotation test.

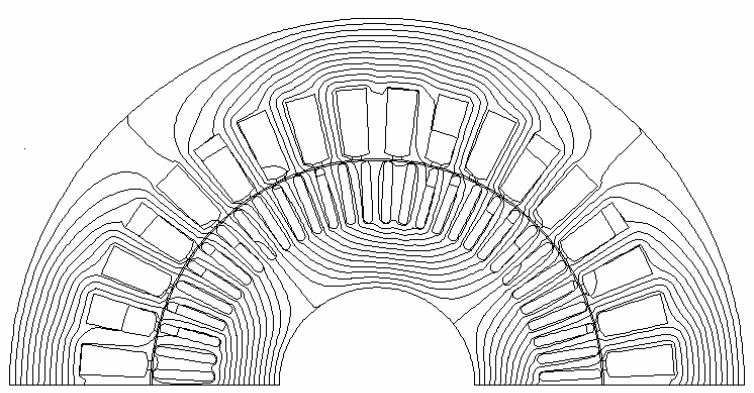

Fig. 15 Flux line plot at approximately full load condition
The main issue of the paper namely to address the uncertainty of stray load measurement has been presented under the hypothesis of theory on a wide variety of tests.

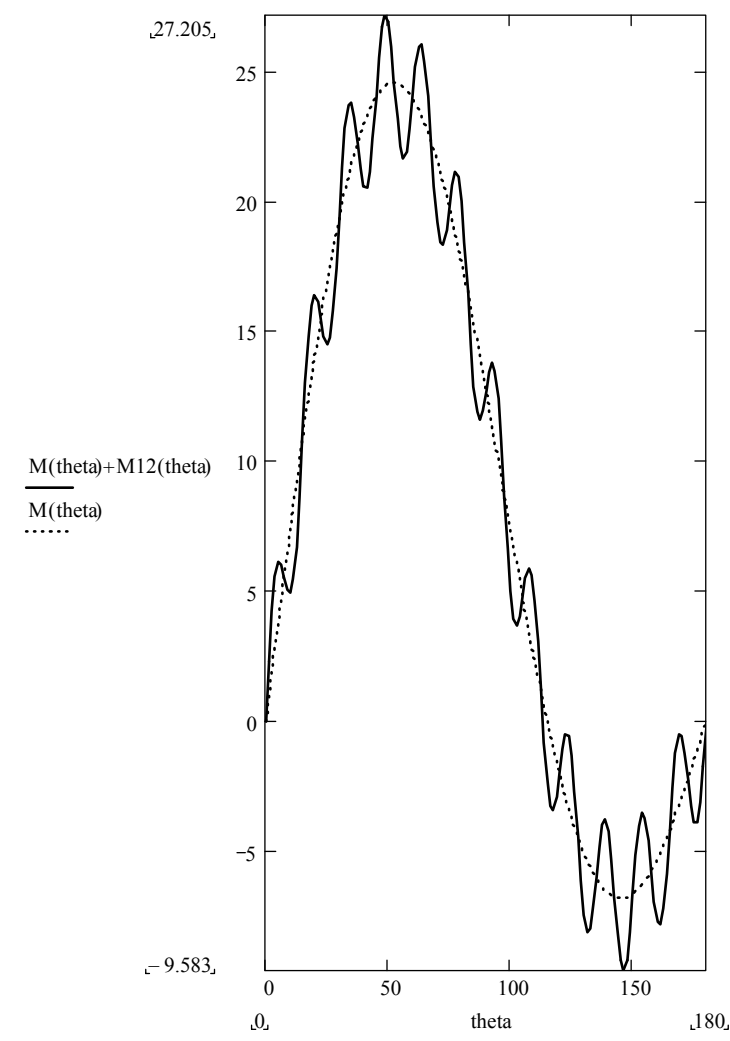

Fig. 16 Driving Torque against pole angle for a mixed drive $\mathrm{SM}+\mathrm{AM}_{\mathrm{SM}}$

\section{References}

[1] L. Dreyfus, Theorie der zusätzlichen Eisenverluste in Drehstromasynchronmotoren, Archiv für Elektrotechnik Bd. XX, 1928, p. 37-87, 188-298.

[2] A.A: Jimoh, R.D. Findlay, M. Poloujadoff, Stray Losses in Induction machines: Part I, Definition, Origin and Measurement, Part II, Calculation and Reduction, IEEE Transactions on Power Apparatus and Systems, Vol. PAS-104, N0. 6, June 1985, p.1500-1512.

[3] Electric Machinery committee, IEEE Std. 112-1999, IEEE Standard Test Procedure for Polyphase Induction Motors and Generators.

[4] H. E. Linkh, Ein Beitrag zur Bestimmung der Zusatzverluste in Drehstromasynchronmotoren, Archiv für Elektrotechnik Bd. XXIII, 1929, p. 19-39.

[5] F. Taegen, R. Walczak, Experimental verification of stray load losses in cage induction motors under no-load, full-load and reverse rotation test conditions, Archiv für Elektrotechnik Bd. LXX, 1987, p. 255-263.

[6] H. Jordan, E. Richter, G. Röder, Ein einfaches Verfahren zur Messung der Zusatzverluste in Asynchronmaschinen, Elektrotechnische Zeitschrift ETZ-A, Bd. 88, 1967. 